\title{
Magnetic properties and resistive switching in mixture films and nanolaminates consisting of iron and silicon oxides grown by atomic layer deposition
}

Cite as: J. Vac. Sci. Technol. A 38, 042405 (2020); https://doi.org/10.1116/6.0000212 Submitted: 26 March 2020 . Accepted: 28 May 2020 . Published Online: 17 June 2020

(iD) Kaupo Kukli, (D) Marianna Kemell, (D) Helena Castán, (D) Salvador Dueñas, (iD) Joosep Link, (iD) Raivo Stern, (D) Mikko J. Heikkilä, (D) Taivo Jõgiaas, (D) Jekaterina Kozlova, (D) Mihkel Rähn, (D) Kenichiro Mizohata, (D) Mikko Ritala, and (iD) Markku Leskelä

\section{COLLECTIONS}

Paper published as part of the special topic on Atomic Layer Deposition (ALD) ALD2021
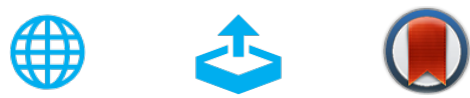

\section{ARTICLES YOU MAY BE INTERESTED IN}

\section{Consistency and reproducibility in atomic layer deposition}

Journal of Vacuum Science \& Technology A 38, 020804 (2020); https://

doi.org/10.1116/1.5140603

Area-selective atomic layer deposition of molybdenum oxide

Journal of Vacuum Science \& Technology A 38, 042406 (2020); https://

doi.org/10.1116/6.0000219

Atomic layer deposition of $\mathrm{HfO}_{2}$ films using carbon-free tetrakis(tetrahydroborato)hafnium and water

Journal of Vacuum Science \& Technology A 38, 042407 (2020); https://

doi.org/10.1116/6.0000053

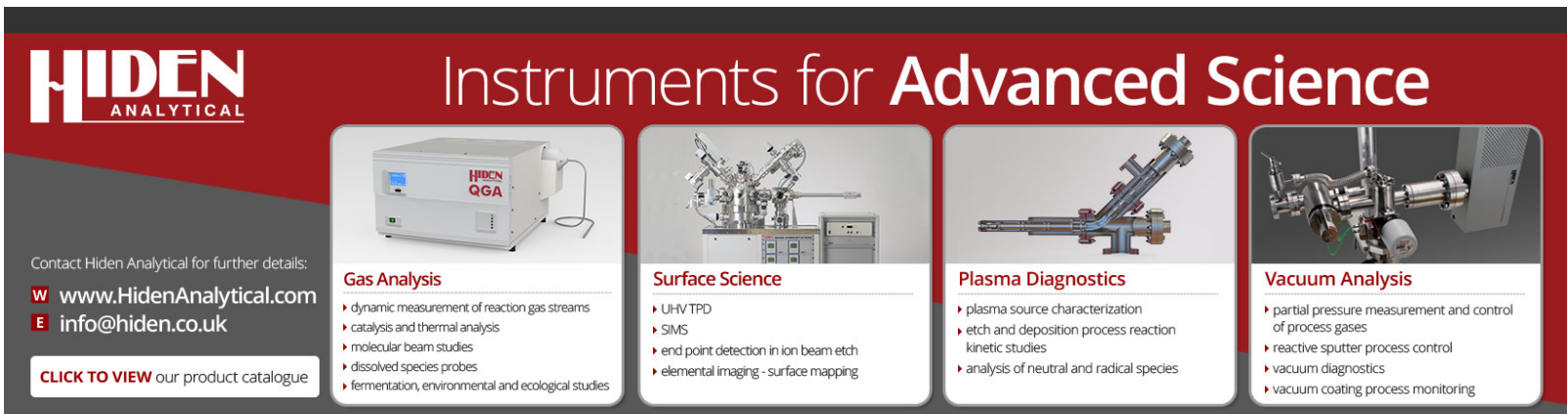




\title{
Magnetic properties and resistive switching in mixture films and nanolaminates consisting of iron and silicon oxides grown by atomic layer deposition
}

Cite as: J. Vac. Sci. Technol. A 38, 042405 (2020); doi: $10.1116 / 6.0000212$

Submitted: 26 March 2020 . Accepted: 28 May 2020 .

Published Online: 17 June 2020

Kaupo Kukli, ${ }^{1, a)}$ (iD Marianna Kemell, ${ }^{7}$ (D) Helena Castán, ${ }^{2}$ (D) Salvador Dueñas, ${ }^{2}$ (D) Joosep Link, ${ }^{3}$ (iD Raivo Stern, ${ }^{3}$ (iD Mikko J. Heikkilä, ${ }^{7}$ (D) Taivo Jõgiaas, ${ }^{4}$ (D) Jekaterina Kozlova, ${ }^{4}$ (D) Mihkel Rähn, ${ }^{4}$ (D) Kenichiro Mizohata, ${ }^{5}$ (D) Mikko Ritala, ${ }^{\top}$ (iD and Markku Leskelä ${ }^{1}$ (D)

\author{
AFFILIATIONS \\ ${ }^{7}$ Department of Chemistry, University of Helsinki, P.O. Box 55, Fl-00014 Helsinki, Finland \\ ${ }^{2}$ Department of Electronics, University of Valladolid, Paseo Belén, 15, 47011 Valladolid, Spain \\ ${ }^{3}$ National Institute of Chemical Physics and Biophysics, Akadeemia tee 23, EE-12618 Tallinn, Estonia \\ ${ }^{4}$ Institute of Physics, University of Tartu, W. Ostwald 1, 50411 Tartu, Estonia \\ ${ }^{5}$ Accelerator Laboratory, Department of Physics, University of Helsinki, P.O. Box 43, Fl-00014 Helsinki, Finland
}

Note: This paper is part of the 2021 Special Topic Collection on Atomic Layer Deposition (ALD).

a)E-mail: kaupo.kukli@ut.ee

\begin{abstract}
$\mathrm{SiO}_{2}-\mathrm{Fe}_{2} \mathrm{O}_{3}$ mixture films and nanolaminates were grown by atomic layer deposition from iron trichloride, hexakis(ethylamino)disilane, and ozone at $300{ }^{\circ} \mathrm{C}$. Orthorhombic $\varepsilon-\mathrm{Fe}_{2} \mathrm{O}_{3}$ was identified in $\mathrm{Fe}_{2} \mathrm{O}_{3}$ reference films and in $\mathrm{Fe}_{2} \mathrm{O}_{3}$ layers grown to certain thicknesses between amorphous $\mathrm{SiO}_{2}$ layers. $\mathrm{SiO}_{2}-\mathrm{Fe}_{2} \mathrm{O}_{3}$ films could be magnetized in external fields, exhibiting saturation and hysteresis in nonlinear magnetization-field curves. Electrical resistive switching, markedly dependent on the ratio of the component oxides, was also observed in films with proper composition. For relatively conductive films, application of small signal measurements allowed one to record memory maps with notable squareness and defined distinction between high and low conductance states.
\end{abstract}

Published under license by AVS. https://doi.org/10.1116/6.0000212

\section{INTRODUCTION}

Multilayers, superlattices, and nanolaminates consisting of different metal oxides are attractive for many applications ranging from optical filters to mechanically resistant coatings. Multilayering chemically and structurally distinctive materials may allow one to tailor physical properties characteristic of component layers. For instance, electrically or magnetically functional nanomaterials can be combined and the degree of their structural ordering can be controlled in periodical stacks with mechanical constraints or electronic charge barriers. Henceforth, one could simultaneously modify the growth of magnetic nanocrystalline materials and improve insulating properties in the composites. In this regard, one can propose that nanolaminate structures consisting of oxides of silicon and iron enable materials demonstrating saturative magnetization in a medium exhibiting tunable insulating behavior.

Layered composites of amorphous $\mathrm{SiO}_{2}$ and structurally ordered $\mathrm{Fe}_{2} \mathrm{O}_{3}$ particles containing hematite, $\alpha-\mathrm{Fe}_{2} \mathrm{O}_{3}$, ${ }^{1,2}$ maghemite, $\gamma-\mathrm{Fe}_{2} \mathrm{O}_{3},{ }^{3-5}$ and magnetite, $\mathrm{Fe}_{3} \mathrm{O}_{4}$, ${ }^{6,7}$ as crystallographic phases have earlier been fabricated and studied in several works. In these composites, nonlinear magnetization of the solid media was achieved and recorded. It is also worth noting that, besides magnetic materials, also other, mostly catalytic, applications of powdered $\mathrm{SiO}_{2}-\mathrm{Fe}_{2} \mathrm{O}_{3}$ composites have been found prospective, whereby the composites were prepared by sputtering, ${ }^{8}$ hydrothermal synthesis, ${ }^{9}$ and coevaporation of $\mathrm{Si}$ and $\mathrm{Fe}$ in an oxygen 
ambient. ${ }^{10}$ The latter composites contained the hematite phase of $\mathrm{Fe}_{2} \mathrm{O}_{3}$.

With regard to the behavior of single metal oxides as resistive switching media in electric fields, both $\mathrm{SiO}_{2}{ }^{11-14}$ and $\mathrm{Fe}_{2} \mathrm{O}_{3}{ }^{15}$ have earlier been separately studied. Spintronic effects in $\mathrm{Fe}_{2} \mathrm{O}_{3}$ films became observable due to the current-induced magnetic ordering followed by decreased scattering of polarized electrons, allowing a current-controlled low resistance state (LRS) and a voltagecontrolled high resistance state (HRS). ${ }^{15}$ Demonstration of both tunable conductivity and magnetic polarization in as-deposited material layer of any particular compound should be of interest. Evaluation of resistive switching in $\mathrm{SiO}_{2}-\mathrm{Fe}_{2} \mathrm{O}_{3}$ composites or layered stacks has not yet been specifically targeted, though. Some papers have, however, described the performance of memristortype devices comprising both $\mathrm{SiO}_{2}$ and $\mathrm{Fe}_{2} \mathrm{O}_{3}$ films in double-layer structures. $^{16,17}$

Earlier, in a few studies, electrical control of ferromagnetism has been addressed and, partially, described. Coexistence of nonlinear saturative magnetization and resistive switching has been observed in pulsed laser deposited $\mathrm{HfO}_{2} / \mathrm{Nb}: \mathrm{SrTiO}_{3}$ based films, ${ }^{18}$ in pulsed laser deposited $\mathrm{TiO}_{2}$ film based structures, ${ }^{19}$ and also in far more complex quaternary metal oxide layers prepared by wet chemistry and spin-coating. ${ }^{20}$ In the latter case, the oxide films consisted partially of ferrite compounds. Very generally, iron oxide thin films may be considered one of the natural choices for easily and remanently magnetizing media, but they have not been considered and exploited as insulating dielectrics. As was mentioned above, resistive switching in iron oxide based media has in a few cases been already reported. ${ }^{15-17}$ The otherwise interesting phenomenon observed and described as multilevel switching in such films may have been, partially, caused also by internal heterogeneity of the iron oxide phase composition. Nevertheless, the exploitation of iron oxide in the form of both magnetizing and resistively switching material layers appears as an intriguing task, provided that the electrical leakage currents through iron oxide components can be reduced. In addition, the application of chemical gas-phase deposition routes to homogeneous large-area thin films, in particular, atomic layer deposition (ALD), should be adapted, in order to conveniently enable multilayering of constituent compounds at moderate process temperatures.

ALD as a method generally suited to the growth of uniform thin films on arbitrarily shaped substrates can be applied for the growth of artificially structured multilayers composed of different oxides. $\mathrm{SiO}_{2}$ films have earlier been grown by ALD from $\mathrm{Si}_{2}$ (NHEt) ${ }_{6}$ and $\mathrm{O}_{3}$ (Ref. 21) and studied as constituent in $\mathrm{AlSiO}_{\mathbf{x}}$ mixtures. ${ }^{22}$ Growth of $\varepsilon-\mathrm{Fe}_{2} \mathrm{O}_{3}$ films by ALD from $\mathrm{FeCl}_{3}$ and $\mathrm{H}_{2} \mathrm{O}$ has also been reported earlier. ${ }^{23}$

In the present study, mixed films and nanolaminates of crystalline iron oxide and amorphous silicon oxide were grown by ALD from iron trichloride, $\mathrm{FeCl}_{3}$, hexakis(ethylamino)disilane, i.e., $\mathrm{Si}_{2}(\mathrm{NHEt})_{6}$, and ozone, $\mathrm{O}_{3}$, precursors at a substrate temperature fixed at $300^{\circ} \mathrm{C}$. Magnetization in external magnetic fields as well as resistive switching behavior under electrical voltage pulses were separately examined in materials in their as-deposited state. The relative contents of iron and silicon oxides were modified in superlatticelike nanolaminate structures in order to initiate the crystal growth in the iron oxide constituent layers intensely enough to give rise to hysteretic magnetization. Concurrently, it was of interest to study, whether the combination of silicon oxide in the multilayers with leaky iron oxides could lower the leakage currents at levels low enough to allow switching between high and low resistivity states under alternating sampling bias voltages.

\section{EXPERIMENT}

The films were grown in a commercial hot-wall flow-type F120 ALD reactor ${ }^{24}$ (ASM Microchemistry, Ltd.). The iron oxide films were grown using $\mathrm{FeCl}_{3}$, and silicon oxide films using hexakis (ethylamino)disilane, $\mathrm{Si}_{2}(\mathrm{NHEt})_{6}$, also denoted as AHEAD (Air Liquide). Ozone was exploited as the oxygen precursor. Ozone was produced with a Wedeco Ozomatic Modular $4 \mathrm{HC}$ ozone generator from oxygen (99.999\%, Linde Gas). The estimated ozone concentration output of the generator was about $100 \mathrm{~g} / \mathrm{m}^{3}$. $\mathrm{Si}_{2}(\mathrm{NHEt})_{6}$ was evaporated at $65-67^{\circ} \mathrm{C}$ and $\mathrm{FeCl}_{3}$ at $145-150{ }^{\circ} \mathrm{C}$. The growth temperature was held at $300^{\circ} \mathrm{C}$. The deposition cycle sequences for both $\mathrm{Fe}_{2} \mathrm{O}_{3}$ and $\mathrm{SiO}_{2}$ were 2.0-1.0-2.0-1.0 s for cation precursor-purge-ozone-purge lengths.

The substrates were cut out of wafers of undoped $\mathrm{Si}(100)$ covered with a $1.5-2.0 \mathrm{~nm}$ thick wet chemically grown $\mathrm{SiO}_{2}$. Electrically conducting substrates were also used, based on (100) silicon with a resistivity of $0.014-0.020 \Omega \mathrm{cm}$, i.e., Si boron-doped to the concentrations up to $5 \times 10^{18}-1 \times 10^{19} / \mathrm{cm}^{3}$, and coated with a $10 \mathrm{~nm}$ thick titanium nitride layer. TiN had been chemical vapor deposited using $\mathrm{TiCl}_{4} / \mathrm{NH}_{3}$ process in an ASM A412 Large Batch $300 \mathrm{~mm}$ reactor at Fraunhofer IPMS-CNT. The $\mathrm{SiO}_{2}-\mathrm{Fe}_{2} \mathrm{O}_{3}$ films were grown to thicknesses ranging from $\sim 30$ to $50 \mathrm{~nm}$. The numbers of $\mathrm{SiO}_{2}$ and $\mathrm{Fe}_{2} \mathrm{O}_{3}$ deposition cycles were varied separately in order to change the thicknesses of the constituent metal oxide layers and the $\mathrm{Fe}$ to $\mathrm{Si}$ ratio of the films. In this way, films having different artificial structures were deposited, ranging from those with $\mathrm{SiO}_{2}$ doped or mixed in low amounts with $\mathrm{Fe}_{2} \mathrm{O}_{3}$ to $\mathrm{SiO}_{2}-\mathrm{Fe}_{2} \mathrm{O}_{3}$ nanolaminates enabling the growth of $\mathrm{Fe}_{2} \mathrm{O}_{3}$ nanocrystals. The growth cycle sequences applied for the different samples are presented in Table I.

Energy dispersive $\mathrm{x}$-ray spectrometry (EDX) was applied for the measurement of the relative iron and silicon contents by a Hitachi S-4800 scanning electron microscope (SEM) equipped with an Oxford INCA 350 EDX spectrometer. In order to avoid interference from the silicon substrates while measuring the silicon content, all the samples were, in parallel, grown on pieces of silicon wafer and aluminum foil. The EDX spectra were measured at

TABLE I. List of $\mathrm{Fe}_{2} \mathrm{O}_{3}-\mathrm{SiO}_{2}$ films grown to the thicknesses and possessing iron to silicon elemental ratios measured by EDX.

\begin{tabular}{lcc}
\hline \hline ALD growth cycle sequences & Thickness & Fe:Si ratio \\
\hline $500 \times \mathrm{Fe}_{2} \mathrm{O}_{3}$; a reference iron oxide film & $28 \mathrm{~nm}$ & \\
$250 \times \mathrm{Fe}_{2} \mathrm{O}_{3}+20 \times \mathrm{SiO}_{2}+250 \times \mathrm{Fe}_{2} \mathrm{O}_{3}$ & $50 \mathrm{~nm}$ & $11: 1$ \\
$4 \times\left[100 \times \mathrm{Fe}_{2} \mathrm{O}_{3}+20 \times \mathrm{SiO}_{2}\right]+100 \times \mathrm{Fe}_{2} \mathrm{O}_{3}$ & $47 \mathrm{~nm}$ & $5: 1$ \\
$4 \times\left[75 \times \mathrm{Fe}_{2} \mathrm{O}_{3}+50 \times \mathrm{SiO}_{2}\right]+75 \times \mathrm{Fe}_{2} \mathrm{O}_{3}$ & $37 \mathrm{~nm}$ & $2: 1$ \\
$10 \times\left[25 \times \mathrm{Fe}_{2} \mathrm{O}_{3}+2 \times \mathrm{SiO}_{2}\right]+25 \times \mathrm{Fe}_{2} \mathrm{O}_{3}$ & $48 \mathrm{~nm}$ & $6: 1$ \\
$10 \times\left[25 \times \mathrm{SiO}_{2}+4 \times \mathrm{Fe}_{2} \mathrm{O}_{3}\right]+25 \times \mathrm{SiO}_{2}$ & $44 \mathrm{~nm}$ & $0.7: 1$ \\
\hline \hline
\end{tabular}


$20 \mathrm{keV}$ from films deposited on the $\mathrm{Al}$ foil. The beam current and spectrometer gain were determined from a calibration measurement performed under the same beam conditions. The calculations were done on the basis of $\mathrm{Fe} \mathrm{K}_{\alpha}$ and $\mathrm{Si} \mathrm{K}_{\alpha}$ x-ray lines using a GMRFILM program. ${ }^{25}$ Contents of residual light elements in the selected samples were determined by time-of-flight elastic recoil detection analysis (TOF-ERDA). ${ }^{26}$ TOF-ERDA was performed with a $5 \mathrm{MV}$ tandem accelerator using $50 \mathrm{MeV}{ }^{127} \mathrm{I}^{+}$ion beam. For the film thickness calculations, the film densities were estimated based on the Fe:Si ratios.

The thicknesses of the films were evaluated either by $\mathrm{x}$-ray reflectometry (XRR) or by EDX spectroscopy. XRR was performed using a PANalytical X'Pert Pro MPD x-ray diffractometer with $\mathrm{Cu}$ $\mathrm{K} \alpha$ source using a $1 / 16^{\circ}$ divergence slit, $\mathrm{Cu}$ attenuator, and parallel plate collimator slit. The density, thickness, and roughness of the layers were acquired by fitting a theoretical model to the measured data using either REFLECTIVITY 1.2 (PANalytical) or REFLEX35 (Ref. 27) software. By using the same equipment, grazing incidence $\mathrm{x}$-ray diffraction analysis was carried out in order to determine the phases formed in the iron oxide layers, using $\mathrm{CuK} \alpha$ radiation (1.5406 $\AA$ ), $1 / 4^{\circ}$ divergence slit, and parallel beam optics. The reflection peaks were indexed and phases were determined after Rietveld analysis using the program PROFEX (ver. 3.11.1). ${ }^{28}$ Lamellae of selected nanolaminates on different substrates were prepared for transmission electron microscopy using FEI Helios Nanolab ${ }^{\mathrm{TM}} 600$ DualBeam $^{\mathrm{TM}}$ scanning microscope equipped with a focused ion beam module and an Omniprobe model 100.7 in situ nanomanipulator. High-resolution transmission electron microscopy studies for the characterization of the cross sections of the nanolaminate structures were carried out using FEI Titan Themis 200 instrument with a field emission gun operated at $200 \mathrm{kV}$.

In order to carry out electrical measurements, metal-insulator-metal type structures were prepared on the conducting substrates. Top electrodes with an area of $0.052 \mathrm{~mm}^{2}$ were formed by electron beam evaporation of $120 \mathrm{~nm}$ thick Al/Ti dots through a shadow mask, with the Ti layer directly contacting the $\mathrm{SiO}_{2}-\mathrm{Fe}_{2} \mathrm{O}_{3}$ nanolaminates. Admittance-voltage and current-voltage measurements were carried out in a light-proof and electrically shielded box. Samples were electrically characterized in both d.c. and a.c. regimes using a Keithley 4200SCS semiconductor analyzer. The bias voltage was applied to the top electrode, while the bottom electrode was grounded. To record the admittance parameters, a small signal of $30 \mathrm{mV}$ r.m.s. was superimposed with the d.c. bias voltage. In accord with the observations, the experimental frequency did not affect the resistive switching behavior in the range of $20 \mathrm{kHz}-1 \mathrm{MHz}$. Magnetic measurements were performed using the vibrating sample magnetometer option of the Quantum Design 14T Physical Property Measurement System by scanning the magnetic field from -50000 to +50000 Oe (from -397.9 to $+397.9 \mathrm{kA} / \mathrm{m}$ ) parallel to the film surface at $5 \mathrm{~K}$ and at room temperature.

\section{RESULTS AND DISCUSSION}

\section{A. Structure and composition}

XRR measurements were conducted on selected samples to examine whether the component oxide layers were distinctively deposited in the stacks. The measurements revealed that multilayer structures have feasibly been formed (Fig. 1). The relatively high maxima in the pattern were unambiguously characteristic of superlatticelike structures and indicative of sharp interfaces between the constituent material layers, whereas the distance between the shorter period oscillations was inversely proportional to the total nanolaminate thickness. In general, the period of the superlattice maxima becomes gradually longer or shorter as the bilayer thickness decreases or increases, respectively. ${ }^{29-32}$ The measured patterns were in a good agreement with the simulations giving proof of not only a nanolaminate structure but also of appreciable layer thickness uniformity (Fig. 1).

The XRR patterns of $\mathrm{SiO}_{2}-\mathrm{Fe}_{2} \mathrm{O}_{3}$ nanolaminates were satisfactorily fitted (Fig. 1) using a model with four equal bilayers and an $\mathrm{Fe}_{2} \mathrm{O}_{3}$ top layer. $\mathrm{An} \mathrm{SiO}_{2}$ layer with a thickness of 1.9-2.2 nm and a roughness of $0.3-0.6 \mathrm{~nm}$ between the nanolaminate and the silicon substrate had to be taken into account in order to reach the satisfactory match between the measured and modeled curves.

Selected nanolaminate films were analyzed by TEM (Fig. 2). The TEM results visualized that the films indeed consisted of defined periodical multilayers. Nanolaminate structures were grown on all substrates: $\mathrm{SiO}_{2} / \mathrm{Si}$ substrates (used in magnetic measurements), TiN/Si (used for electrical evaluation), and $\mathrm{Al}$ (used in EDX measurements to enable the measurements of $\mathrm{Si}$ in the films). One can notice the somewhat wavy and rough nature of the alternating layers and diffuse interfaces between the constituent oxides. This is most probably caused by the strong tendency of $\mathrm{Fe}_{2} \mathrm{O}_{3}$ to crystallize, which increases morphological nonuniformities. The roughness caused by the nanocrystalline nature of the iron oxide component is also reflected in XRR curves that are deformed at $2 \Theta$ angles higher than $3^{\circ}$ (Fig. 1).

The $\mathrm{Fe}_{2} \mathrm{O}_{3}$ films grown in this study clearly started to crystallize in their as-deposited states (Fig. 3). The extent of crystallization and the phase composition was markedly influenced by the content of $\mathrm{SiO}_{2}$ in the mixed or laminated films, as expected. It is to be noted, at first, that most of the reflections in the diffractograms could be assigned as those of either the cubic maghemite (ICDD card 4-755) or rhombohedral hematite (ICDD card 33-664). Apparently, the crystallized part of the thin film material contained a mixture of iron oxide phases. However, the clear reflection peaks at $37^{\circ}$ and $61^{\circ}$ did not match with any of the common phases, i.e., maghemite, magnetite, or hematite. At the same time, all the reflection peaks apparent in the diffractogram of 25-30 nm thick $\mathrm{Fe}_{2} \mathrm{O}_{3}$ film grown without $\mathrm{SiO}_{2}$ additives could be attributed to the nanocrystalline orthorhombic $\varepsilon-\mathrm{Fe}_{2} \mathrm{O}_{3}$ (ICSD card 173024) [Fig. 3(a)].

Furthermore, in a triple-layer structure comprising two $\mathrm{Fe}_{2} \mathrm{O}_{3}$ films embedding a single very thin $\mathrm{SiO}_{2}$ layer, the phase unambiguously recognized was $\varepsilon-\mathrm{Fe}_{2} \mathrm{O}_{3}$ [Fig. 3(b)], as concluded on the basis of diffraction peaks with somewhat lower intensity and larger width compared to those of the bare $\mathrm{Fe}_{2} \mathrm{O}_{3}$ film. Expectedly, insertion of even small amounts of $\mathrm{SiO}_{2}$ into the host iron oxide decreased the intensity of crystallization in the as-deposited $\mathrm{Fe}_{2} \mathrm{O}_{3}$ films. The $\varepsilon-\mathrm{Fe}_{2} \mathrm{O}_{3}$ polymorph has earlier been obtained with the ALD process using $\mathrm{FeCl}_{3}$ and $\mathrm{H}_{2} \mathrm{O}$ as precursors. ${ }^{23}$ It has also been stated that $\varepsilon-\mathrm{Fe}_{2} \mathrm{O}_{3}$ is an intermediate phase on the polymorphous route from $\gamma-\mathrm{Fe}_{2} \mathrm{O}_{3}$ to $\alpha-\mathrm{Fe}_{2} \mathrm{O}_{3}$, and $\varepsilon-\mathrm{Fe}_{2} \mathrm{O}_{3}$ exists only in the form of nanocrystalline material due to surface energy related factors. ${ }^{33}$ Since ALD proceeds via gas-phase deposition forming 

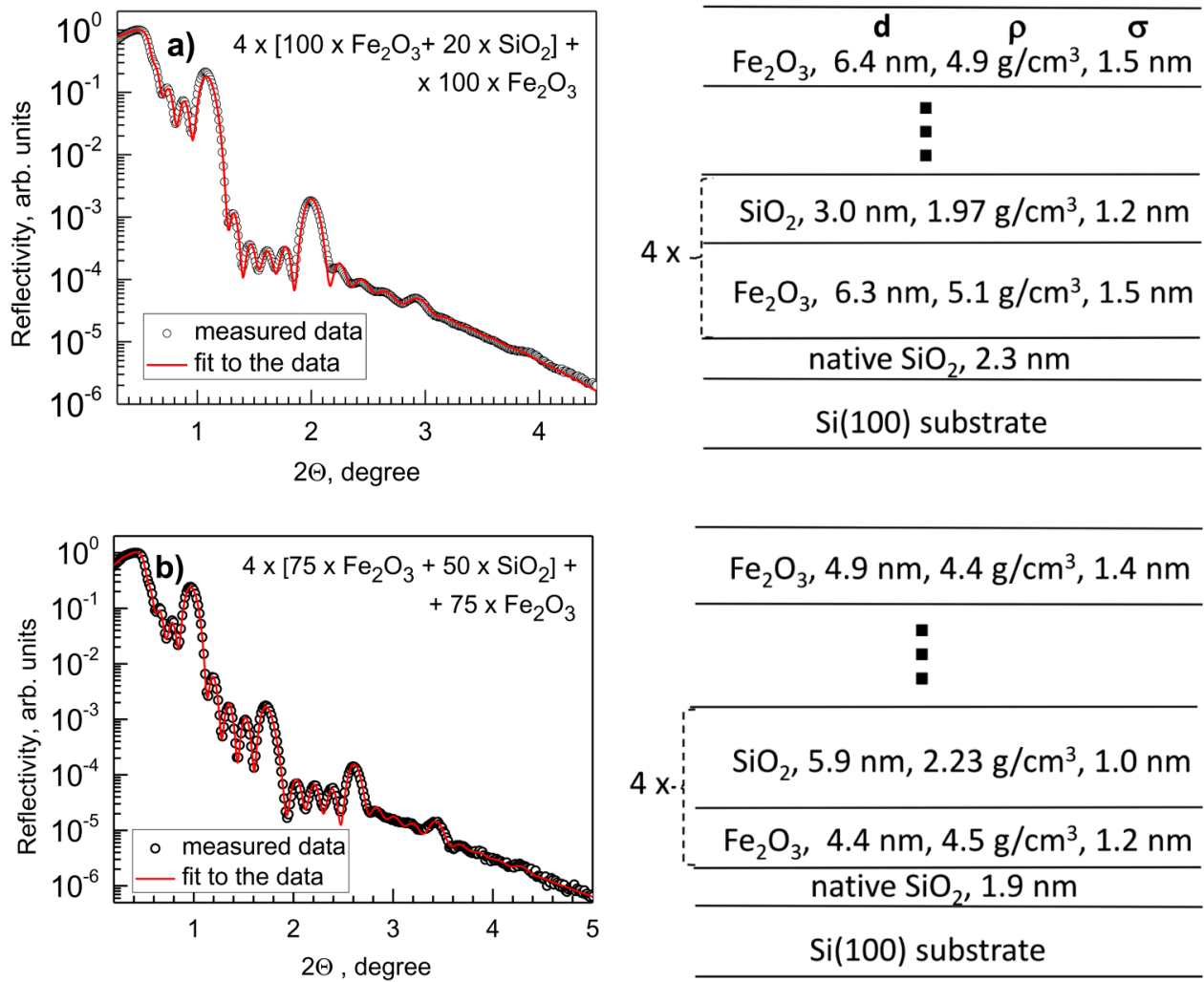

$\mathrm{Fe}_{2} \mathrm{O}_{3}, 4.9 \mathrm{~nm}, 4.4 \mathrm{~g} / \mathrm{cm}^{3}, 1.4 \mathrm{~nm}$

\begin{tabular}{c}
\hline $\mathrm{Fe}_{2} \mathrm{O}_{3}, 4.9 \mathrm{~nm}, 4.4 \mathrm{~g} / \mathrm{cm}^{3}, 1.4 \mathrm{~nm}$ \\
\hline \\
$\frac{\mathrm{SiO}_{2}, 5.9 \mathrm{~nm}, 2.23 \mathrm{~g} / \mathrm{cm}^{3}, 1.0 \mathrm{~nm}}{\mathrm{Fe}_{2} \mathrm{O}_{3}, 4.4 \mathrm{~nm}, 4.5 \mathrm{~g} / \mathrm{cm}^{3}, 1.2 \mathrm{~nm}}$ \\
$\frac{\text { native SiO }}{2} 1.9 \mathrm{~nm}$ \\
Si(100) substrate
\end{tabular}

FIG. 1. Measured and fitted x-ray reflection patterns from $\mathrm{SiO}_{2}-\mathrm{Fe}_{2} \mathrm{O}_{3}$ nanolaminate films grown using ALD cycle sequences indicated by the labels (left column) and schematic representation of the nanolaminate structures with layer thickness, $d$, mass density, $\rho$, and roughness, $\sigma$, as fitting results (right column). In both panels (a) and (b) of the left column, every other data point is omitted for the sake of clarity. layers with slowly and monotonously increasing thickness, stabilization of intermediate phases in their nanocrystalline form can indeed be expected.

The appearance of the $\varepsilon-\mathrm{Fe}_{2} \mathrm{O}_{3}$ phase in the composites and mixture films with silicon oxide has also been observed before. For instance, magnetic colloidal rod-shaped mesoporous particles have been made of silica $\left(\mathrm{SiO}_{2}\right)$ and iron oxide $\left(\varepsilon-\mathrm{Fe}_{2} \mathrm{O}_{3}\right)$ using a solvent-free melting impregnation method to form iron oxide nanocrystals inside silica nanopores. ${ }^{34} \varepsilon-\mathrm{Fe}_{2} \mathrm{O}_{3}$ nanoparticles have been formed by heat-treating amorphous $\mathrm{Fe}-\mathrm{Si}-\mathrm{O}$ films deposited by magnetron sputtering of $\left(\alpha-\mathrm{Fe}_{2} \mathrm{O}_{3}\right)_{1-\mathrm{x}}\left(\mathrm{SiO}_{2}\right)_{\mathrm{x}}$ composites. ${ }^{35}$ Furthermore, $\varepsilon-\mathrm{Fe}_{2} \mathrm{O}_{3}$ has also been formed by implantation of iron oxide particles in $\mathrm{SiO}_{2}$ glass ${ }^{36}$ or impregnation of mesoporous silica matrix by iron nitrate.

To examine the stability of the polymorphs and distinction between the different phases, that is $\gamma-\mathrm{Fe}_{2} \mathrm{O}_{3}$ (maghemite), $\varepsilon-\mathrm{Fe}_{2} \mathrm{O}_{3}$, and $\alpha-\mathrm{Fe}_{2} \mathrm{O}_{3}$ (hematite), selected films were heated in air at $800{ }^{\circ} \mathrm{C}$. Expectedly, the $\varepsilon-\mathrm{Fe}_{2} \mathrm{O}_{3}$ was turned into the hematite phase, that is clearly distinguishable from the orthorhombic polymorph $\varepsilon-\mathrm{Fe}_{2} \mathrm{O}_{3}$ [Fig. 3(c)].

In the $\mathrm{Fe}_{2} \mathrm{O}_{3}-\mathrm{SiO}_{2}$ films consisting of relatively thinner composite layers, the crystal growth of iron oxide became naturally restricted, as revealed by the XRD. Figure 4 depicts diffractograms measured from $\mathrm{Fe}_{2} \mathrm{O}_{3}-\mathrm{SiO}_{2}$ nanolaminates and mixture films with increasing relative silicon content. In these structures, certain, although weak, crystallographic ordering was still observable, owing to the onset of crystallization in the thin, but chemically still distinct, iron oxide layers. In such cases, the ambiguity of the phase determination increased. However, the reflections apparent in the diffractograms could still be assigned as those characteristic of $\varepsilon-\mathrm{Fe}_{2} \mathrm{O}_{3}$ (Fig. 4). One can also presume that the probability of the formation of metastable crystalline oxide polymorphs increases with the decrease in the layer thickness of these oxides. Thus, the assignment of the XRD patterns to $\varepsilon-\mathrm{Fe}_{2} \mathrm{O}_{3}$ (Fig. 4) becomes justified.

Figure 5 represents scanning electron microscope images of the surfaces of the as-deposited $\mathrm{Fe}_{2} \mathrm{O}_{3}-\mathrm{SiO}_{2}$ films. One can see that the surface of a $28 \mathrm{~nm}$ thick $\mathrm{Fe}_{2} \mathrm{O}_{3}$ film, not mixed with $\mathrm{SiO}_{2}$, consists of uniform features, which may well characterize a polycrystalline material with grain boundaries developed up to the very surface and thus clearly visible. A decrease in the thickness of the topmost $\mathrm{Fe}_{2} \mathrm{O}_{3}$ layer in the nanolaminates apparently caused a slight decrease in the grain size on the surface. However, the XRR results (Fig. 1) did not reveal any significant differences in the roughness of the top layers of the laminate structures. At the same time, the average grain size, as estimated from the SEM images, also decreased along with the increase in the number of intermediate $\mathrm{SiO}_{2}$ growth cycles. Surfaces of the films where the topmost layer was amorphous $\mathrm{SiO}_{2}$ (Fig. 5) remained, expectedly, relatively featureless and smoother compared to the multilayers terminated by iron oxide.

Selected samples were evaluated by ToF-ERDA in order to determine contents of light residual elements averaged throughout the film thicknesses. The triple layer grown using the ALD cycle 

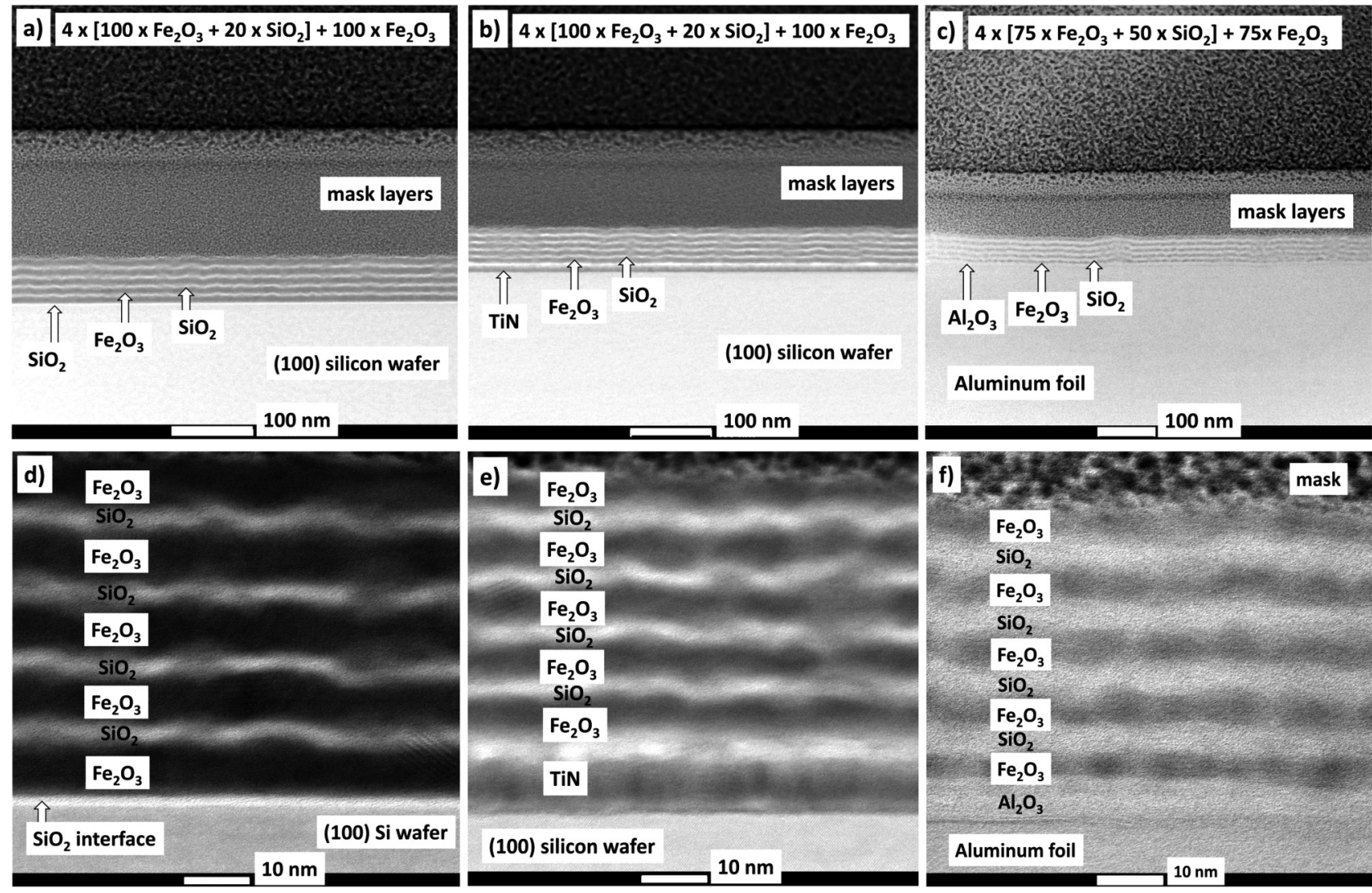

FIG. 2. Transmission electron microscopy images of $\mathrm{Fe}_{2} \mathrm{O}_{3}-\mathrm{SiO}_{2}$ nanolaminate films grown on $\mathrm{SiO}_{2} / \mathrm{Si}$ substrates [(a) and (d)], Si substrates covered by a TiN layer [(b) and (e)], and aluminum foil p(c) and (f)]. The corresponding growth cycle sequences are indicated on the panels in the upper row. The layers of distinct chemical composition constituting the film stacks are labeled correspondingly.

sequence of $250 \times \mathrm{Fe}_{2} \mathrm{O}_{3}+20 \times \mathrm{SiO}_{2}+250 \times \mathrm{Fe}_{2} \mathrm{O}_{3}$ consisted of $37.8 \pm 0.4$ at. $\% \mathrm{Fe}, 60.0 \pm 0.6$ at. $\% \mathrm{O}$, and $1.6 \pm 0.4$ at. \% Si. The contents of residual impurities were measured as low as $0.27 \pm 0.04$ at. \% chlorine, $0.18 \pm 0.04$ at. $\%$ nitrogen, $0.18 \pm 0.04$ at. \% carbon, and $0.44 \pm 0.12$ at. \% hydrogen.

The nanolaminate grown on $\mathrm{TiN}$ using the ALD cycle sequence of $4 \times\left[100 \times \mathrm{Fe}_{2} \mathrm{O}_{3}+20 \times \mathrm{SiO}_{2}\right]+100 \times \mathrm{Fe}_{2} \mathrm{O}_{3}$ consisted of $23.2 \pm 0.3$ at. $\% \mathrm{Fe}, 52.6 \pm 0.5$ at. $\% \mathrm{O}$, and $5.5 \pm 0.5$ at. $\%$ Si. The residual impurities were detected as $0.39 \pm 0.04$ at. $\% \mathrm{Cl}$, $7.9 \pm 0.2$ at. $\% \mathrm{~N}, 0.26 \pm 0.02$ at. $\% \mathrm{C}$, and $0.74 \pm 0.12$ at. $\% \mathrm{H}$. In this stack of the films grown on TiN-covered silicon substrate, the contribution from the TiN electrode layer to the composition was as high as $9.4 \pm 0.2$ at. \% $\mathrm{Ti}$, which also explains the high nitrogen content detected in the film.

ToF-ERDA on the film that exhibited the most well defined resistive switching behavior, i.e., the film grown using the sequence of $\left.4 \times\left[75 \times \mathrm{Fe}_{2} \mathrm{O}_{3}+50 \times \mathrm{SiO}_{2}\right]+75 \times \mathrm{Fe}_{2} \mathrm{O}_{3}\right]$ (Fig. 8), revealed that the film contained $18.7 \pm 0.3$ at. $\% \mathrm{Fe}, 61.8 \pm 1.7$ at. $\% \mathrm{O}$, and $9.90 \pm 1.3$ at. \% Si. The contents of residual impurities were $2.10 \pm 0.17$ at. $\%$ chlorine, $0.76 \pm 0.20$ at. $\%$ nitrogen, $0.40 \pm 0.22$ at. $\%$ carbon, and $5.8 \pm 2.8$ at. \% hydrogen.
The ToF-ERDA results indicated that the impurity contents were appreciably low in the as-deposited laminate films. The presence of such impurities is, nevertheless, to be taken into account, as they naturally affect the structure and performance of magnetic and electric films by increasing the defect densities. However, to improve the electrical performance of the $\mathrm{SiO}_{2}-\mathrm{Fe}_{2} \mathrm{O}_{3}$ films, the presence of silicon and iron oxides in comparable amounts or at least in contents of the same order of magnitude seem to be necessary in multilayers.

\section{B. Magnetic behavior}

Figure 6 depicts magnetization curves measured for selected samples in an external magnetic field at room temperature. One can see that the magnetization in the $\mathrm{SiO}_{2}-\mathrm{Fe}_{2} \mathrm{O}_{3}$ films was easy, proceeding nonlinearly against the external field, and tended to saturate at sufficiently high fields exceeding 5000-10 000 Oe applied in the plane of the film surface. Hysteresis in the magnetizationfield loops remained rather narrow, and the coercive field was thus weak. Analogous behavior in some iron oxide-silicon oxide composites has been observed earlier. ${ }^{34,38}$ In the present study, the 

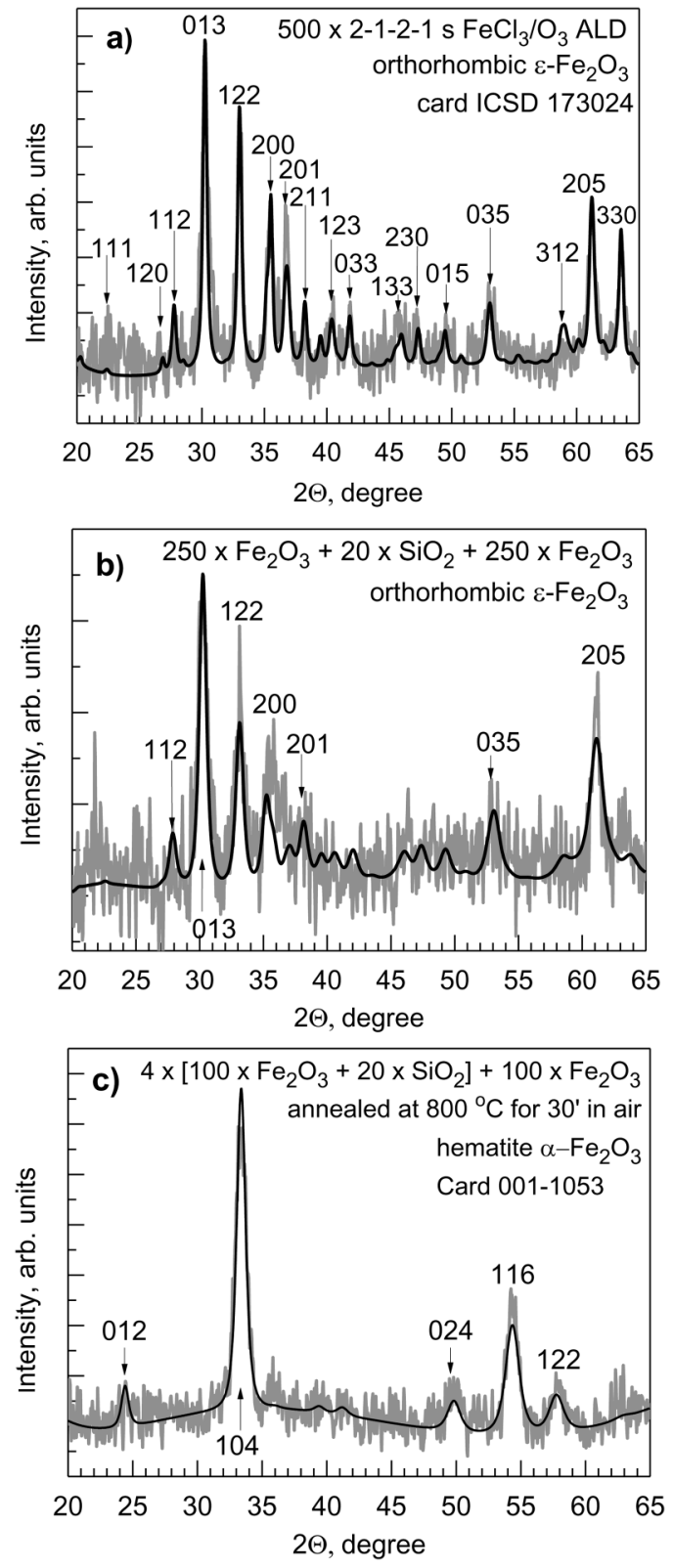

FIG. 3. Grazing incidence x-ray diffractograms from (a) $28 \mathrm{~nm}$ thick $\mathrm{Fe}_{2} \mathrm{O}_{3}$ film, (b) $50 \mathrm{~nm}$ thick $\mathrm{Fe}_{2} \mathrm{O}_{3}$ film embedding a $2-3 \mathrm{~nm}$ thick $\mathrm{SiO}_{2}$ interlayer, and (c) a nanolaminate film after annealing at $800^{\circ} \mathrm{C}$ in air. Experimental and fitted diffractograms are represented by bold gray and solid black curves, respectively. Reflexes above the noise level are designated as those belonging to the $\mathrm{Fe}_{2} \mathrm{O}_{3}$ polymorphs and indicated by the corresponding labels for the epsilon-phase in top and middle panels and hematite in bottom panel.

magnetization-field curves measured from the films grown using cycle sequences of $4 \times\left[75 \times \mathrm{Fe}_{2} \mathrm{O}_{3}+50 \times \mathrm{SiO}_{2}\right]+75 \times \mathrm{Fe}_{2} \mathrm{O}_{3}$ (Fig. 6) and $4 \times\left[100 \times \mathrm{Fe}_{2} \mathrm{O}_{3}+20 \times \mathrm{SiO}_{2}\right]+100 \times \mathrm{Fe}_{2} \mathrm{O}_{3}$ (not shown) displayed insignificant coercive fields at room temperature. and saturation

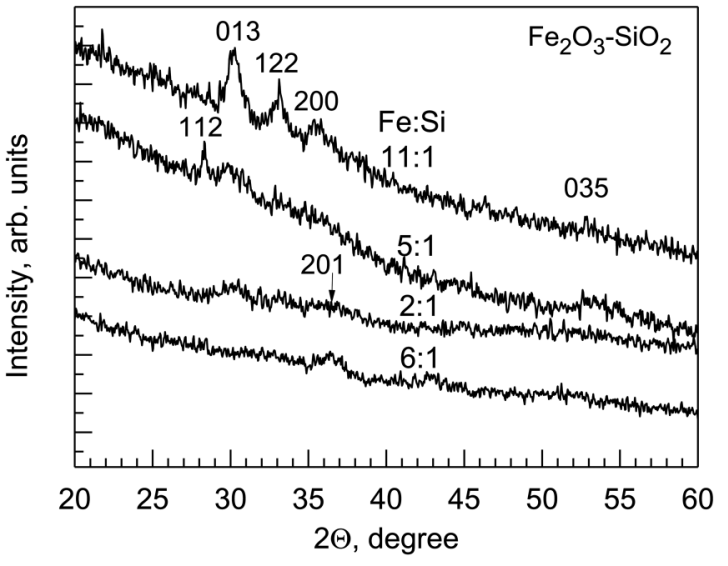

FIG. 4. Grazing incidence x-ray diffractograms from as-deposited $\mathrm{Fe}_{2} \mathrm{O}_{3}$ films mixed or laminated with $\mathrm{SiO}_{2}$ with molar Fe:Si ratios (EDX), indicated by the labels. For the description of the growth cycle sequences, see Table I.

magnetization did not exceed $2.5 \times 10^{-4}$ and $2.5 \times 10^{-5} \mathrm{emu} / \mathrm{g}$, respectively. At low temperature, i.e., at $5 \mathrm{~K}$, the coercivity increased noticeably up to $1.2 \mathrm{kOe}$ (not shown) and $4.6 \mathrm{kOe}$ (Fig. 7), respectively, whereas the saturation magnetization values remained in the same order of magnitude as in the high-temperature measurements.

In accord with the literature, the orthorhombic $\varepsilon-\mathrm{Fe}_{2} \mathrm{O}_{3}$ has emerged as possibly the most interesting phase of iron oxide, mainly due to its ferromagnetic performance with a remarkable coercive field at low and room temperatures, as well as magnetoelectric properties. ${ }^{38-46}$ As already noted, $\varepsilon-\mathrm{Fe}_{2} \mathrm{O}_{3}$ has been recognized as a metastable phase of iron oxide, which can be achieved only in nanocrystalline material upon polymorphous transformation between maghemite $\left(\gamma-\mathrm{Fe}_{2} \mathrm{O}_{3}\right)$ and hematite $\left(\alpha-\mathrm{Fe}_{2} \mathrm{O}_{3}\right)$ phases. ${ }^{33,47-49}$ Magnetic $\varepsilon-\mathrm{Fe}_{2} \mathrm{O}_{3}$ nanoparticles have earlier been prepared often by wet chemical synthesis. ${ }^{38,44,45,50,51}$

In the present study, the magnetic behavior of the triple $\mathrm{Fe}_{2} \mathrm{O}_{3}-\mathrm{SiO}_{2}-\mathrm{Fe}_{2} \mathrm{O}_{3}$ layer, in which the content of $\varepsilon-\mathrm{Fe}_{2} \mathrm{O}_{3}$ was significant (Fig. 2), resembles that observed by $\mathrm{Li}$ et al. ${ }^{34}$ In the latter work, iron oxide nanocrystals were stabilized within spaces confined inside mesoporous silica after annealing in order to crystallize the $\varepsilon-\mathrm{Fe}_{2} \mathrm{O}_{3}$ phase, and the coercivities were in the range of 2000-2500 Oe, as measured below room temperature, i.e., at $200 \mathrm{~K}$. It is also worth noting that in another work by Kubičková et al $^{37}$ devoted to the investigations of the properties of homogeneously mixed $\mathrm{SiO}_{2}-\mathrm{Fe}_{2} \mathrm{O}_{3}$ suspensions, the magnetic coercivities measured at $300 \mathrm{~K}$ were decreased down to zero, whereas the coercivity of the reference $\varepsilon-\mathrm{Fe}_{2} \mathrm{O}_{3}$ sample without $\mathrm{SiO}_{2}$ extended to $20 \mathrm{kOe}$ in the same study.

One could notice certain deformation of the magnetizationfield loop measured on the triple $\mathrm{Fe}_{2} \mathrm{O}_{3}-\mathrm{SiO}_{2}-\mathrm{Fe}_{2} \mathrm{O}_{3}$ layer (Fig. 6, lower panel). When reaching zero fields during sweeping the external field strength, the response of the magnetization intensifies, even indicating a tendency to discontinuous response to the field and a "kink" like feature close to the zero field. Such a kink in the magnetization curve near the zero field has been proposed to be 

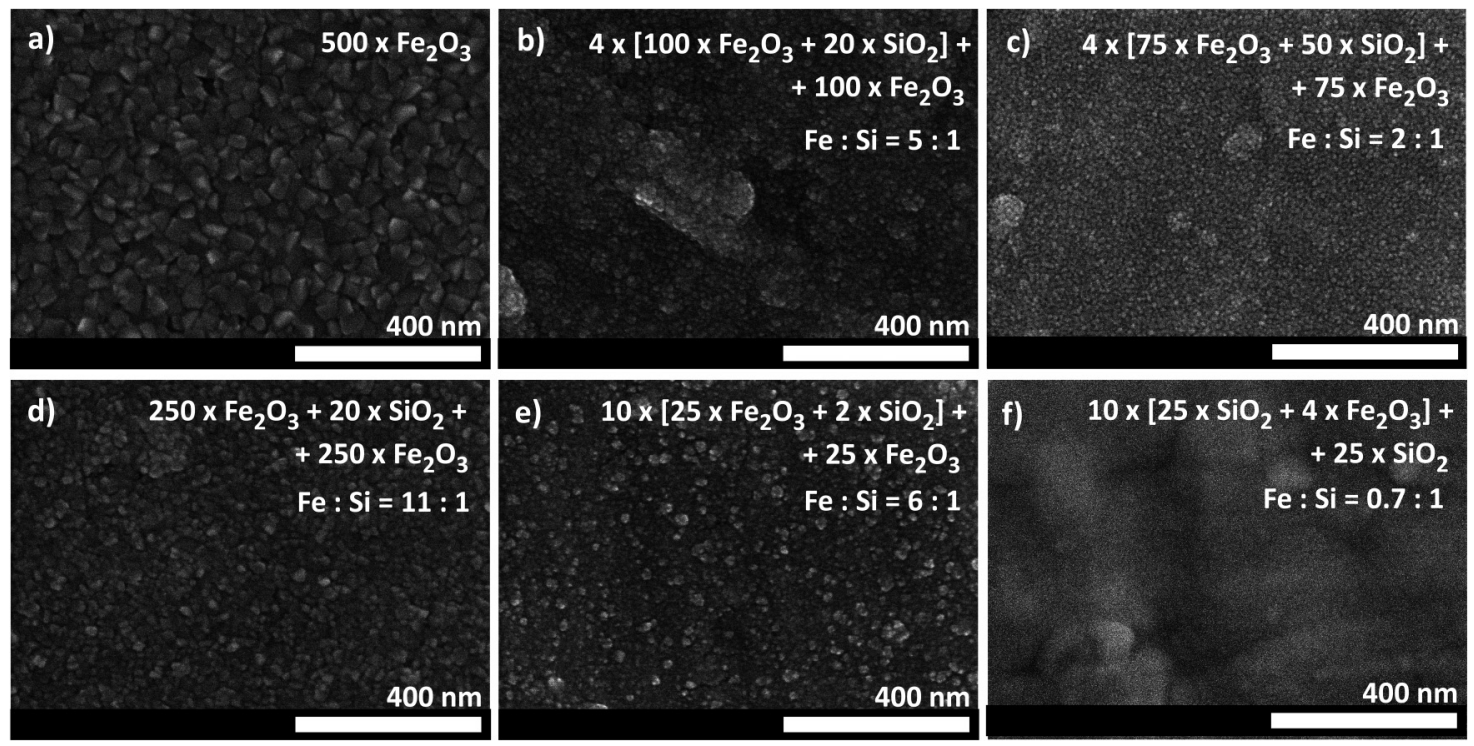

FIG. 5. Scanning electron microscopy images from the surfaces of $\mathrm{Fe}_{2} \mathrm{O}_{3}-\mathrm{SiO}_{2}$ films as-deposited using cycle sequences indicated by the labels.

indicative of the presence of ferrimagnetic $\gamma-\mathrm{Fe}_{2} \mathrm{O}_{3}$ polymorph impurities. ${ }^{45}$ It is worth noting that analogous tendencies in the development of such abrupt kinks have been observed in several works, ${ }^{34,38,40,41,44}$ although structural analyses have not always revealed a multiphase structure.

Figure 7 depicts magnetization-field loops measured from selected samples at a low temperature, $5 \mathrm{~K}$. One can see again that the magnetization in the $\mathrm{SiO}_{2}-\mathrm{Fe}_{2} \mathrm{O}_{3}$ films is easy, nonlinear, and saturating with increasing fields applied in the film plane in both opposing directions. The hysteresis in the magnetization-field loop at $5 \mathrm{~K}$ is considerably wider compared to that at room temperature and the coercive field becomes comparable to those observed earlier. In several cases earlier, composites containing iron oxide had to be annealed markedly after their synthesis in order to properly crystallize the material and, concurrently, achieve appreciable coercive field even at low measurement temperatures. For instance, Popovici et al. ${ }^{51}$ observed coercivities exceeding $20 \mathrm{kOe}$ at room temperature after annealing a $\mathrm{Fe}_{2} \mathrm{O}_{3}-\mathrm{SiO}_{2}$ sample at $1100^{\circ} \mathrm{C}$, whereas lower annealing temperatures did not provide sufficient degree of crystallization and accompanying significant coercivity.

One approach has been to grow oriented $\varepsilon-\mathrm{Fe}_{2} \mathrm{O}_{3}$ layers by laser ablation at $700-900{ }^{\circ} \mathrm{C}$ to the thickness of $50 \mathrm{~nm}$ on monocrystalline ferrite substrates, as reported by Thai et al. ${ }^{39}$ In these films, coercivity reaching $2 \mathrm{kOe}$ was measured at $350 \mathrm{~K}$. Yet, in another study conducted by Balaev et al., ${ }^{43} \varepsilon-\mathrm{Fe}_{2} \mathrm{O}_{3}$ particles of about $5-10 \mathrm{~nm}$ in diameter were incorporated in composites with porous silica gel as the matrix and calcined at $900^{\circ} \mathrm{C}$. Coercive fields in the range of 6-12 kOe could be achieved in magnetization-field loops, when measured at $300 \mathrm{~K}$. Dubrovskiy et al. ${ }^{40}$ have described the effect of the $\varepsilon-\mathrm{Fe}_{2} \mathrm{O}_{3}$ particle size to the magnetic response. In their study, $\varepsilon-\mathrm{Fe}_{2} \mathrm{O}_{3}$ particles were impregnated in silica pores by wet chemical synthesis from iron sulfate solution and heat treated at $900^{\circ} \mathrm{C}$ for $4 \mathrm{~h}$ afterward. Upon that procedure, measurable amounts of $\varepsilon-\mathrm{Fe}_{2} \mathrm{O}_{3}$ particles with diameters in the range of $5-10 \mathrm{~nm}$ were produced, demonstrating coercivities within 5-6 kOe. Thus, the reference data seem to imply that high-temperature processing of $\mathrm{Fe}_{2} \mathrm{O}_{3}-\mathrm{SiO}_{2}$ nanocomposites has been a prerequisite to effective room temperature magnetic polarization and memory effects. In the present paper, however, appreciable magnetic polarization has been achieved in the as-deposited $\mathrm{Fe}_{2} \mathrm{O}_{3}-\mathrm{SiO}_{2}$ multilayer structures containing $\varepsilon-\mathrm{Fe}_{2} \mathrm{O}_{3}$ nanocrystallites.

According to the knowledge published to date, $\varepsilon-\mathrm{Fe}_{2} \mathrm{O}_{3}$ is a phase that can display complex magnetic properties. At $\sim 490 \mathrm{~K}$, $\varepsilon-\mathrm{Fe}_{2} \mathrm{O}_{3}$ changes from a paramagnetic state to an ordered, supposedly canted, antiferromagnetic state. With decreasing temperature, the coercivity of $\varepsilon-\mathrm{Fe}_{2} \mathrm{O}_{3}$ rapidly increases and reaches $\sim 20000$ Oe $(2 \mathrm{~T})$ at room temperature and a maximum of $\sim 22000 \mathrm{Oe}(2.2 \mathrm{~T})$ at $200 \mathrm{~K}$. Below $200 \mathrm{~K}$, the coercivity has been seen to decrease drastically, reaching zero at $\sim 100 \mathrm{~K}$. Below that, the coercivity recovers and strengthens up to $5000 \mathrm{Oe}(0.5 \mathrm{~T})$ at $2 \mathrm{~K}^{40} \mathrm{In}$ our samples, the coercivity measured at room temperature was much smaller than that expected for $\varepsilon-\mathrm{Fe}_{2} \mathrm{O}_{3}$. The coercivity was close to zero in the laminate and about 700 Oe for the $\mathrm{Fe}_{2} \mathrm{O}_{3}-\mathrm{SiO}_{2}-\mathrm{Fe}_{2} \mathrm{O}_{3}$ trilayer structure. As mentioned above, the deformed shape of the hysteresis loop of the trilayer at room temperature might indicate the existence of more than one phase with different coercivities in the films. It is to be noted, that even if the XRD results allowed one to consider the formation of $\varepsilon-\mathrm{Fe}_{2} \mathrm{O}_{3}$ as the dominant phase in some samples, formation and coexistence of additional hematite phase cannot be excluded, and the multiphase character of the nanocrystalline material is therefore still possible. Different phases would all contribute to the physical properties of the phase mixture. In this regard, Kant et al. ${ }^{52}$ have synthesized stable $\alpha-\mathrm{Fe}_{2} \mathrm{O}_{3}$ particles with dimensions ranging from 13 to $63 \mathrm{~nm}$ and 

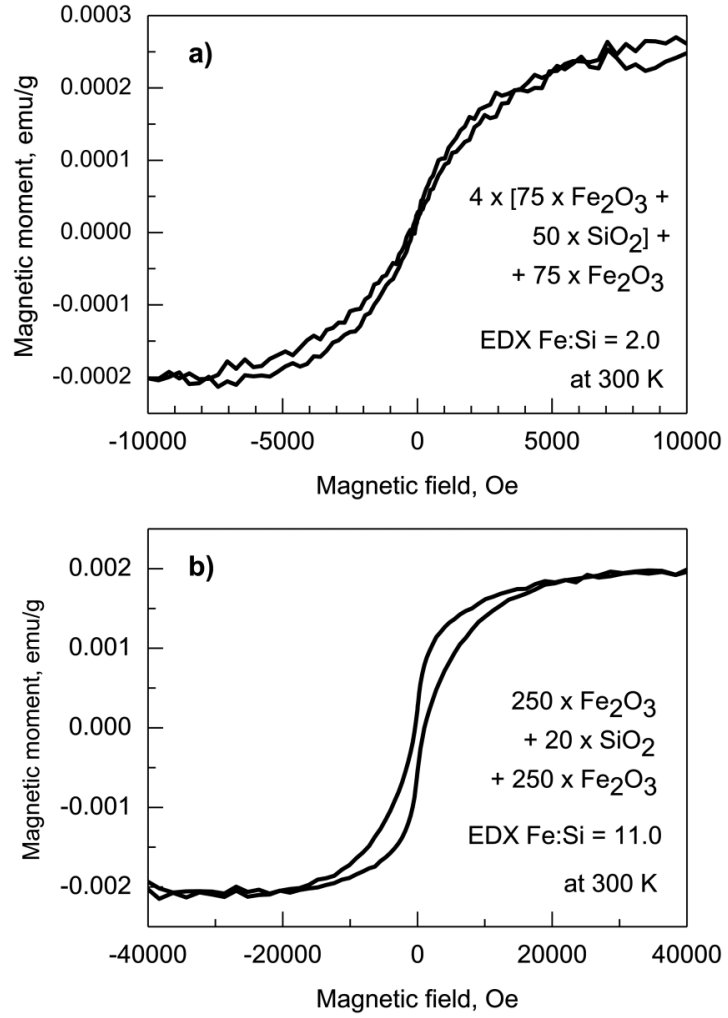

FIG. 6. Room temperature magnetization curves measured from periodical $\mathrm{Fe}_{2} \mathrm{O}_{3}-\mathrm{SiO}_{2}$ nanolaminate (upper panel) and $\mathrm{Fe}_{2} \mathrm{O}_{3}-\mathrm{SiO}_{2}-\mathrm{Fe}_{2} \mathrm{O}_{3}$ triple layer (lower panel) grown using ALD cycle sequences and with $\mathrm{Fe}: \mathrm{Si}$ atomic ratio described by the labels.

also measured relatively moderate coercivity values, $\sim 6000$ Oe at $10 \mathrm{~K}$ and $\sim 27 \mathrm{Oe}$ at $300 \mathrm{~K}$. Therefore, magnetization in such nanolaminates and nanocrystalline oxides can easily vary along with small variations in the phase composition comprising different polymorphs of iron oxide.

\section{Electrical behavior}

Resistive switching behavior was recorded and found to be the most well defined in the $\mathrm{SiO}_{2}-\mathrm{Fe}_{2} \mathrm{O}_{3}$ nanolaminate grown using the ALD cycle sequence of $4 \times\left[75 \times \mathrm{Fe}_{2} \mathrm{O}_{3}+50 \times \mathrm{SiO}_{2}\right]+75 \times \mathrm{Fe}_{2} \mathrm{O}_{3}$ (Fig. 8, topmost panel). The ratio between the high and low resistance states was significant, extending over an order of magnitude in the conventional resistive switching measurements.

It is noteworthy that $\mathrm{Fe}_{2} \mathrm{O}_{3}$ films have less frequently been considered candidates for memristor media, likely due to their strongly polycrystalline nature and accompanying inferior insulating characteristics. Nevertheless, for instance, in a study devoted to the ALD of relatively smooth, uniform, and finely grained $\mathrm{Fe}_{2} \mathrm{O}_{3},{ }^{15}$ resistive switching was studied and observed. Current and resistivity values in the high resistance state could be tuned by varying the maximum voltage used for breaking conductive channels (filaments) during
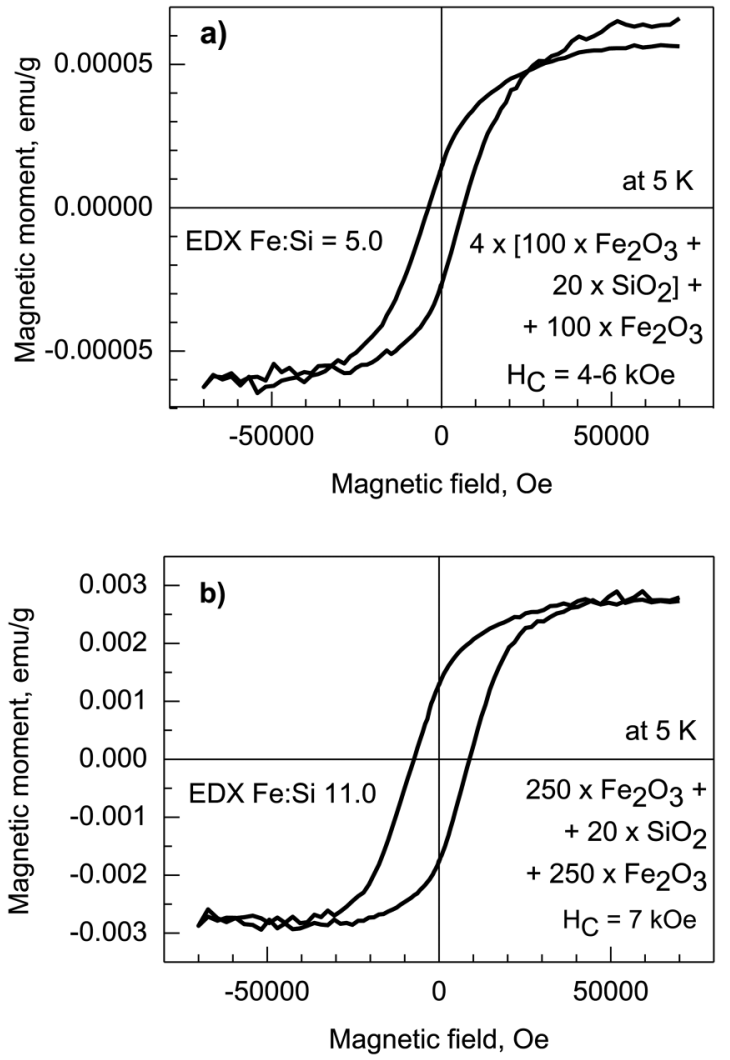

FIG. 7. Magnetization-field curves measured at $5 \mathrm{~K}$ from (a) periodical $\mathrm{Fe}_{2} \mathrm{O}_{3}-\mathrm{SiO}_{2}$ nanolaminate and (b) $\mathrm{Fe}_{2} \mathrm{O}_{3}-\mathrm{SiO}_{2}-\mathrm{Fe}_{2} \mathrm{O}_{3}$ triple layer grown using ALD cycle sequences and with $\mathrm{Fe}: \mathrm{Si}$ atomic ratios described by labels.

resetting the high resistivity. In the present study, however, the $\mathrm{Fe}_{2} \mathrm{O}_{3}$ films alone occurred too conductive and did not allow switching with reliable distinction between low and high resistance states.

Silicon oxide has been studied as one of the most promising switching media. In a study on cosputtering of silicon-rich silicon dioxide films, ${ }^{53}$ conductive pathways formed were supposedly not continuous but rather chains of partially separated silicon nanoinclusions in a highly substoichiometric oxide matrix. These $\mathrm{SiO}_{\mathrm{x}}$-based devices differed, at that time, from most of the other materials studied in that diffusion of metallic ions was not involved in the formation of the conductive paths. ${ }^{53}$ In the present study, however, the as-deposited $\mathrm{SiO}_{2}$ reference films did not exhibit appreciable switching characteristics, which was likely due to the impurities existing in the films.

In a reliable switching medium, the difference between the low and high resistivity states should be at least an order of magnitude, which, in the present study, was observed in the case of the ALD cycle sequence of $4 \times\left[75 \times \mathrm{Fe}_{2} \mathrm{O}_{3}+50 \times \mathrm{SiO}_{2}\right]+75 \times \mathrm{Fe}_{2} \mathrm{O}_{3}$ [Fig. 8(a)]. In these measurements, rectangular sampling voltage pulses were applied to the electrodes on the dielectric layer, with the pulse amplitude increasing within the sequence of pulses. 

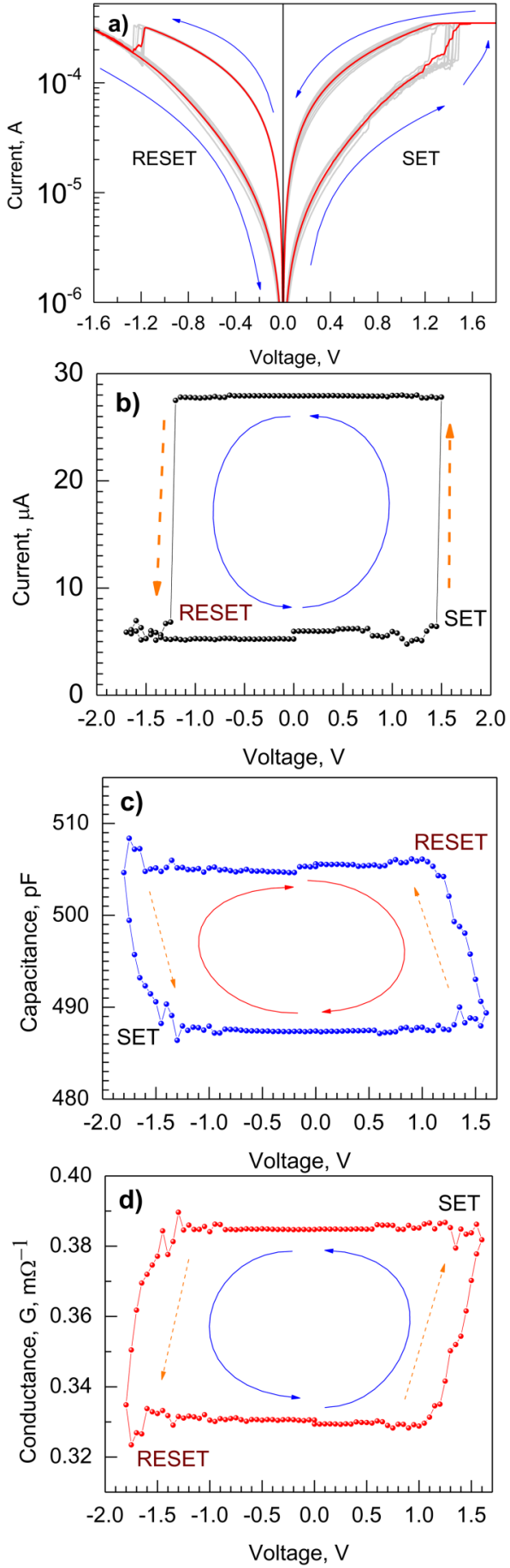

FIG. 8. Current-voltage loops measured (a) in the conventional resistive switching mode, (b) small signal current-voltage memory map, (c) small signal capacitance memory map, and (d) small signal conductance memory map (bottom panel) against sampling voltage pulses applied on $30 \mathrm{~nm}$ thick $\mathrm{SiO}_{2}-\mathrm{Fe}_{2} \mathrm{O}_{3}$ nanolaminate deposited with a cycle sequence of $\left.4 \times\left[75 \times \mathrm{Fe}_{2} \mathrm{O}_{3}+50 \times \mathrm{SiO}_{2}\right]+75 \times \mathrm{Fe}_{2} \mathrm{O}_{3}\right]$.
At the increasing voltage pulses, currents were recorded, forming current-voltage envelope curves until the transition (switching) to the low resistance state (SET) and back to the high resistance state (RESET). However, alternatively to the conventional envelope curves, currents were registered at low-reading voltages of $0.1 \mathrm{~V}$ after passing each sequential sampling voltage pulses. In this case, the measured current values were even more clearly determined by the two resistivity states than in the conventional measurements. Thus, exploitation of the low-reading voltages provided two clearly defined plateaus of current values that were recorded before and after the sequential SET and RESET transitions (Fig. 8, second panel). In this way, current-voltage loops (current memory map) with pronounced squareness were formed by the applied voltages with a distinct memory window between the high and low current states. This measurement method has become useful especially in such cases where the material possesses rather high conduction currents already in the virgin, supposedly high resistivity, state before the formation of the low resistivity state and, therefore, exhibits too small ratios between the high and low resistance states in the conventional measurements. The method has been used earlier to study the performance of some other resistively switching oxides, such as $\mathrm{Ta}_{2} \mathrm{O}_{5}-\mathrm{TiO}_{2}-\mathrm{Ta}_{2} \mathrm{O}_{5}$ or $\mathrm{ZrO}_{2}-\mathrm{Co}_{3} \mathrm{O}_{4}$, ${ }^{54}$ and $\mathrm{Nb}_{2} \mathrm{O}_{5}-\mathrm{SiO}_{2}$ nanolaminates ${ }^{55}$ grown by ALD.

In order to evaluate the capacitive behavior in addition to the direct currents through the dielectric stacks, differential capacitances were measured at a frequency of $500 \mathrm{kHz}$, also between sampling bias voltage pulses (Fig. 8). Admittance parameters were recorded along with sweeping the sampling bias voltage. Conductance, $G$, and capacitance, C, maps over low-reading voltage sampling were recorded, applying a parallel admittance model. ${ }^{56}$ In order to obtain the memory maps for $\mathrm{G}$ and $\mathrm{C}$, return-to-zero voltage pulse sequences were used. Thereby positive voltage pulses of $1 \mathrm{~ms}$ duration were applied while the sample was in its high resistance state. After each sampling voltage pulse, the voltage was returned to $0 \mathrm{~V}$, and the admittance-derived conductance and capacitance values were recorded at $0 \mathrm{~V}$ bias on ac signal only. The amplitude of the sampling voltage pulse was increased linearly until the transition from the high resistance state to the low resistance state occurred, and thereafter correspondingly decreased until the transition back to the high resistance state. The plots of capacitance, C [Fig. 8(c)], and conductance, G [Fig. 8(d)], as functions of the voltage, which can also be termed as the programming voltage in this case, thus constituted the corresponding memory maps.

Analogous measurements were carried out on an $\mathrm{Fe}_{2} \mathrm{O}_{3}-\mathrm{SiO}_{2}-\mathrm{Fe}_{2} \mathrm{O}_{3}$ triple-layered film grown using the ALD cycle sequence of $250 \times \mathrm{Fe}_{2} \mathrm{O}_{3}+20 \times \mathrm{SiO}_{2}+250 \times \mathrm{Fe}_{2} \mathrm{O}_{3}$. This film occurred rather leaky compared to the nanolaminate grown using the ALD cycle ratio of 75:50, described above. The triple-layer sample exhibited rather weakly detectable and thus less significant resistive switching performance with a low ratio between the low and high resistivity states [Fig. 9(a)]. In the $\mathrm{SiO}_{2}-\mathrm{Fe}_{2} \mathrm{O}_{3}$ nanolaminate grown using the ALD cycle sequence of $4 \times\left[75 \times \mathrm{Fe}_{2} \mathrm{O}_{3}+50 \times \mathrm{SiO}_{2}\right]+75 \times \mathrm{Fe}_{2} \mathrm{O}_{3}$ [Fig. 8(a)], the conducting current values measured at $-1 \mathrm{~V}$ during the RESET pulses in low and high resistance states were 2.8 and $1.1 \times 10^{-4} \mathrm{~A}$, respectively, making the LRS to HRS ratio equal to 2.6. In the case of the triple layer [Fig. 9(a)], the corresponding values were 2.8 and $2.0 \times 10^{-4} \mathrm{~A}$, lowering the LRS to HRS ratio to 1.4. 

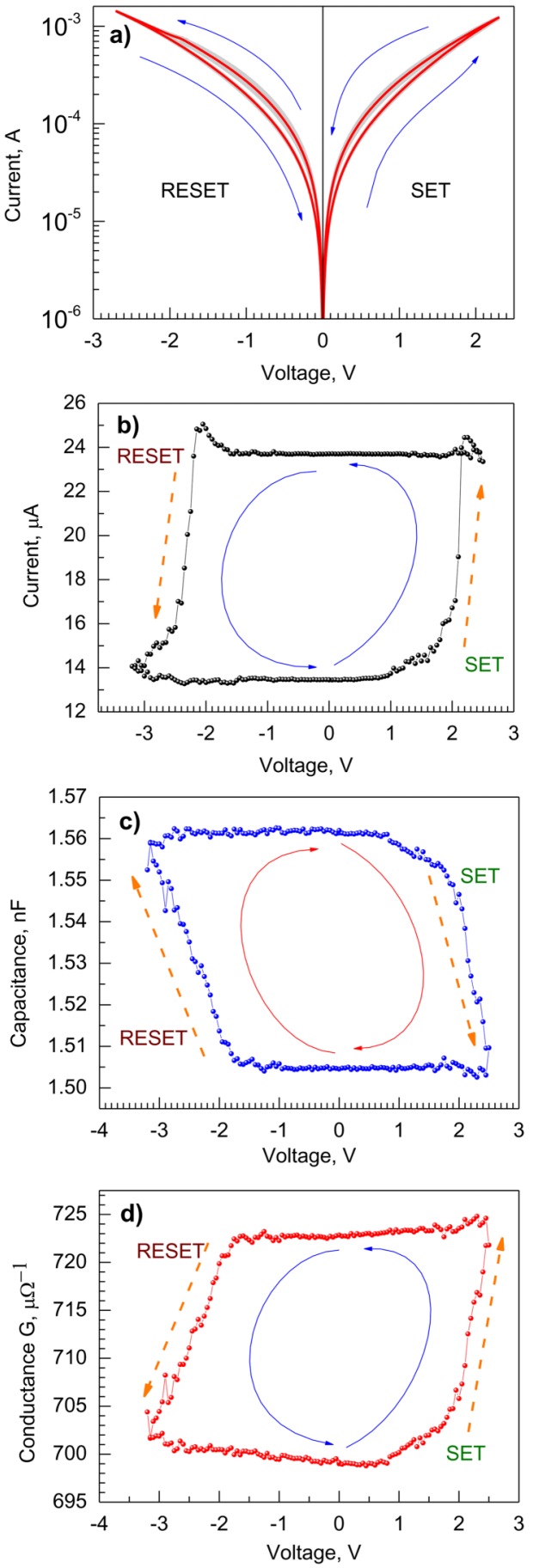

FIG. 9. Current-voltage loops measured (a) in the conventional resistive switching mode, (b) small signal current-voltage memory map, (c) small signal capacitance memory map, and (d) small signal conductance memory map (bottom panel) against sampling voltage pulses applied on $50 \mathrm{~nm}$ thick $\mathrm{SiO}_{2}-\mathrm{Fe}_{2} \mathrm{O}_{3}$ triple layer deposited with a cycle sequence of $250 \times \mathrm{Fe}_{2} \mathrm{O}_{3}+$ $20 \times \mathrm{SiO}_{2}+250 \times \mathrm{Fe}_{2} \mathrm{O}_{3}$
Figure 9 also represents the current-voltage loop measured at low-reading voltages [Fig. 9(b)], as well as capacitance [Fig. 9(c)] and conductance [Fig. 9(d)] memory maps obtained from the admittance measurements at return-to-zero voltages, similar to the case of the nanolaminate described above. From these, one can see that even if the conventional resistive switching property manifests itself poorly, the current measurements in the low-reading regime and admittance measurements at the return-to-zero voltage enable recording memory maps with well defined squareness and distinct differences between the low and high conductivities as well as sharp SET and RESET transition events.

\section{CONCLUSIONS}

The atomic layer deposition method was exploited to grow $\mathrm{SiO}_{2}-\mathrm{Fe}_{2} \mathrm{O}_{3}$ nanolaminate and mixture films on silicon and titanium nitride substrates. The elemental composition of the films could feasibly be modified by changing the ratio of successive ALD cycles for the $\mathrm{SiO}_{2}$ and $\mathrm{Fe}_{2} \mathrm{O}_{3}$ component oxides. The crystal growth of $\mathrm{Fe}_{2} \mathrm{O}_{3}$ was initiated and intensified with the thickness of $\mathrm{Fe}_{2} \mathrm{O}_{3}$ layers in the $\mathrm{SiO}_{2}-\mathrm{Fe}_{2} \mathrm{O}_{3}$ films. Along with the increment in the relative content of iron oxide and its crystallization, nonlinear and saturative magnetization in the films was detected at room temperature and enhanced at $5 \mathrm{~K}$. The $\mathrm{Fe}_{2} \mathrm{O}_{3}$ layers tended to crystallize in the metastable orthorhombic $\varepsilon-\mathrm{Fe}_{2} \mathrm{O}_{3}$ phase, although some contribution of hematite to the phase composition could not be excluded.

Response of the films to the external electric fields was examined. Resistive switching performance with a pronounced window between the low and high resistivity states was recorded in the structures grown using proper ratios between $\mathrm{SiO}_{2}$ and $\mathrm{Fe}_{2} \mathrm{O}_{3}$ growth cycles. Admittance measurements in a small signal regime allowed one to enhance the distinction between the low and high resistance states as well as the squareness of the memory maps.

Among the structures examined, the nanolaminate grown using the ALD cycle sequence of $4 \times\left[75 \times \mathrm{Fe}_{2} \mathrm{O}_{3}+50 \times \mathrm{SiO}_{2}\right]+75 \times \mathrm{Fe}_{2} \mathrm{O}_{3}$ was the one exhibiting clear responses to both magnetic and electric fields. The film consisted of $\sim 4.4 \mathrm{~nm}$ thick $\mathrm{Fe}_{2} \mathrm{O}_{3}$ and $5.9 \mathrm{~nm}$ thick $\mathrm{SiO}_{2}$ layers, was nanocrystalline, possibly comprising orthorhombic $\varepsilon-\mathrm{Fe}_{2} \mathrm{O}_{3}$ phase, and demonstrated saturative and nonlinear magnetization with rather narrow hysteresis at room temperature, as well as resistive switching behavior with the most prominent distinction between low and high resistivity states.

The study has demonstrated that $\mathrm{Fe}_{2} \mathrm{O}_{3}$ films, which are deposited alternately with $\mathrm{SiO}_{2}$ films in multilayered structures, can resemble ferromagnetic nanocrystalline materials, and the electronic leakage currents may become, to a certain extent, suppressed by controlling the contribution from the wide bandgap $\mathrm{SiO}_{2}$. The latter also enables the appearance of resistive switching in the multilayers. In relatively leaky materials, application of small signal measurements still ensure recording of distinct and defined memory performance. With further and more detailed parametrization and scale-up of the process in the future, one may seek the effect of electrical conductivity on magnetization and vice versa, that is, to identify a coupling effect between conductivity and magnetic polarization. 


\section{ACKNOWLEDGMENTS}

This study was partially supported by the Finnish Centre of Excellence in Atomic Layer Deposition (No. 284623), the Spanish Ministry of Economy and Competitiveness and the FEDER program (No. TEC2017-84321-C4-2-R), the European Regional Development Fund project "Emerging orders in quantum and nanomaterials" (No. TK134), and the Estonian Research Agency (Nos. PRG4 and PRG753).

\section{REFERENCES}

'M. Tadic, V. Kusigerski, D. Markovic, I. Milosevic, and V. Spasojevic, Mater. Lett. 63, 1054 (2009).

${ }^{2}$ P. L. Zhu, F. Xue, Z. Liu, Y. L. Fan, Z. M. Jiang, and X. J. Yang, J. Appl. Phys. 106, 043907 (2009).

${ }^{3}$ A. Teleki, M. Suter, P. R. Kidambi, O. Ergeneman, F. Krumeich, B. J. Nelson, and S. E. Pratsinis, Chem. Mater. 21, 2094 (2009).

${ }^{4}$ D. Ortega, J. S. Garitaonandia, M. Ramírez-del-Solar, C. Barrera-Solano, and M. Domínguez, J. Non-Cryst. Solids 354, 5213 (2008).

${ }^{\mathbf{5}}$ C. Păcurariu, E.-A. Tăculescu, R. Ianoşa, O. Marinică, C.-V. Mihali, and V. Socoliuc, Ceram. Int. 41, 1079 (2015).

${ }^{6}$ C.-K. Huang, C.-H. Hou, C.-C. Chen, Y.-L. Tsai, L.-M. Chang, H.-S. Wei, K.-H. Hsieh, and C.-H. Chan, Nanotechnology 19, 055701 (2008).

${ }^{7}$ Y. P. He, S. Q. Wang, C. R. Li, Y. M. Miao, Z. Y. Wu, and B. S. Zou, J. Phys. D Appl. Phys. 38, 1342 (2005).

${ }^{8}$ N. R. Murphy, C. V. Ramana, L. Sun, J. G. Jones, and J. T. Grant, J. Alloys Compd. 708, 947 (2017).

${ }^{9}$ X. Zhang, Y. Niu, Y. Li, Y. Li, and J. Zhao, J. Solid State Chem. 211, 69 (2014).

${ }^{10}$ W. D. Chemelewski, N. T. Hahn, and C. B. Mullins, J. Phys. Chem. C 116, 5255 (2012)

${ }^{11}$ H. Jiang, X. Y. Li, R. Chen, X. L. Shao, J. H. Yoon, X. Hu, C. S. Hwang, and J. Zhao, Sci. Rep. 6, 22216 (2016).

${ }^{12}$ L. Liu, D. Yu, W. Ma, B. Chen, F. Zhang, B. Gao, and J. Kang, Jpn. J. Appl. Phys. 54, 021802 (2015).

${ }^{13}$ J. Yao, Z. Sun, L. Zhong, D. Natelson, and J. M. Tour, Nano Lett. 10, 4105 (2010).

${ }^{14}$ X. Yan, Z. Zhou, B. Ding, J. Zhao, and Y. Zhang, J. Mater. Chem. C 5, 2259 (2017).

${ }^{15}$ S. Porro, K. Bejtka, A. Jasmin, M. Fontana, G. Milano, A. Chiolerio, C. F. Pirri, and C. Ricciardi, Nanotechnology 29, 495201 (2018).

${ }^{16}$ Y.-F. Chang, T.-C. Chang, and C.-Y. Chang, J. Appl. Phys. 110, 053703 (2011).

${ }^{17}$ Y.-F. Chang, Y.-T. Tsai, G.-W. Chang, Y.-E. Syu, Y.-H. Tai, and T.-C. Chang, ECS J. Solid State Sci. Technol. 1, Q91 (2012).

${ }^{18}$ S. Ren, G. Zhu, J. Xie, J. Bu, H. Qin, and J. Hu, J. Phys. Condens. Matter 28, 056001 (2016).

${ }^{19}$ S. Ren, H. Qin, J. Bu, G. Zhu, J. Xie, and J. Hu, Appl. Phys. Lett. 107, 062404 (2015).

${ }^{\mathbf{2 0}}$ M.-C. Kao, H.-Z. Chen, S.-L. Young, K.-H. Chen, J.-L. Chiang, and J.-B. Shi, Materials 10, 1327 (2017).

${ }^{21}$ R. Matero, S. Haukka, and M. Tuominen, ECS Trans. 13, 453 (2008).

${ }^{22}$ Y. Tomczak, K. Knapas, S. Haukka, M. Kemell, M. Heikkilä, M. Ceccato, M. Leskelä, and M. Ritala, Chem. Mater. 24, 3859 (2012).

${ }^{23}$ A. Tanskanen, O. Mustonen, and M. Karppinen, APL Mater. 5, 056104 (2017).
${ }^{24}$ T. Suntola, Thin Solid Films 216, 84 (1992).

${ }^{25}$ R. A. Waldo, Microbeam Analysis (San Francisco, San Francisco, CA, 1988), p. 310.

${ }^{\mathbf{2 6}}$ J. Jokinen, J. Keinonen, P. Tikkanen, A. Kuronen, T. Ahlgren, and K. Nordlund, Nucl. Instrum. Methods Phys. Res. B 119, 533 (1996).

${ }^{27}$ G. Vignaud and Alain Gibaud, J. Appl. Crystallogr. 52, 201 (2019).

${ }^{28} \mathrm{~N}$. Doebelin and R. Kleeberg, J. Appl. Crystallogr. 48, 1573 (2015).

${ }^{29}$ D. Spiga, A. Mirone, G. Pareschi, R. Canestrari, V. Cotroneo, C. Ferrari, C. Ferrero, L. Lazzarini, and D. Vernani, Proc. SPIE 6266, 626616 (2006).

${ }^{30}$ S. Sintonen, S. Ali, O. M. E. Ylivaara, R. L. Puurunen, and H. Lipsanen, J. Vac. Sci. Technol. A 32, $01 \mathrm{~A} 111$ (2014).

${ }^{31}$ J. M. Jensen, A. B. Oelkers, R. Toivola, D. C. Johnson, J. W. Elam, and S. M. George, Chem. Mater. 14, 2276 (2002).

${ }^{32}$ J. Lee and S. Park, J. Korean Phys. Soc. 69, 789 (2016).

${ }^{33}$ L. Machala, J. Tuček, and R. Zbořil, Chem. Mater. 23, 3255 (2011).

${ }^{34}$ J.-G. Li, G. Fornasieri, A. Bleuzen, M. Gich, A. Gloter, F. Bouquet, and M. Impéror-Clerc, Small 12, 5981 (2016).

${ }^{35}$ Y. Masubuchi, Y. Sato, A. Sawada, T. Motohashi, H. Kiyono, and S. Kikkawa, J. Eur. Ceram. Soc. 31, 2459 (2011).

${ }^{36}$ K. Nomura and H. Reuther, J. Radioanal. Nucl. Chem. 287, 341 (2011).

${ }^{37}$ L. Kubíčková, P. Brázda, M. Veverka, O. Kaman, V. Herynek, M. Vosmanská, P. Dvořák, K. Bernášek, and J. Kohout, J. Magn. Magn. Mater. 480, 154 (2019). ${ }^{38}$ J. Tuček, R. Zbořil, A. Namai, and S. Ohkoshi, Chem. Mater. 22, 6483 (2010).

${ }^{39}$ T. M. N. Thai, D. T. Nguyen, N.-S. Lee, J.-S. Rhyee, J. Song, and H.-J. Kim, J. Appl. Phys. 120, 185304 (2016).

${ }^{40}$ A. A. Dubrovskiy, D. A. Balaev, K. A. Shaykhutdinov, O. A. Bayukov, O. N. Pletnev, S. S. Yakushkin, G. A. Bukhtiyarova, and O. N. Martyanov, J. Appl. Phys. 118, 213901 (2015).

${ }^{41}$ M. Gich, A. Roig, C. Frontera, E. Molins, J. Sort, M. Popovici, G. Chouteau, D. Martín y Marero, and J. Nogués, J. Appl. Phys. 98, 044307 (2005).

${ }^{42}$ A. Namai et al., Nat. Commun. 3, 1035 (2012).

${ }^{43}$ D. A. Balaev et al., J. Appl. Phys. 117, 063908 (2015).

${ }^{44}$ J. Kohout, P. Brázda, K. Závěta, D. Kubániová, T. Kmječ, L. Kubičková, M. Klementová, E. Šantavá, and A. Lančok, J. Appl. Phys. 117, 17D505 (2015).

${ }^{45}$ I. Ahamed, R. Pathak, R. Skomski, and A. Kashyap, AIP Adv. 8, 055815 (2018).

${ }^{46}$ J. A. Sans et al., Nat. Commun. 9, 4554 (2018).

${ }^{47}$ Y. El Mendili, J.-F. Bardeau, N. Randrianantoandro, J.-M. Greneche, and F. Grasset, Sci. Technol. Adv. Mater. 17, 597 (2016).

${ }^{48}$ C. Dejoie et al., Sci. Rep. 4, 4941 (2014).

${ }^{49} \mathrm{M}$. Gich, C. Frontera, A. Roig, J. Fontcuberta, E. Molins, N. Bellido, Ch. Simon, and C. Fleta, Nanotechnology 17, 687 (2006).

${ }^{50}$ V. N. Nikolić, M. Tadić, M. Panjan, L. Kopanja, N. Cvjetićanin, and V. Spasojević, Ceram. Int. 43, 3147 (2017).

${ }^{51}$ M. Popovici et al., Chem Mater. 16, 5542 (2004).

${ }^{52}$ R. Kant, D. Kumar, and V. Dutta, RSC Adv. 5, 52945 (2015).

${ }^{53}$ A. Mehonic, S. Cueff, M. Wojdak, S. Hudziak, O. Jambois, C. Labbé, B. Garrido, R. Rizk, and A. J. Kenyon, J. Appl. Phys. 111, 074507 (2012).

${ }^{54}$ S. Dueñas, H. Castán, K. Kukli, M. Mikkor, K. Kalam, T. Arroval, and A. Tamm, ECS Trans. 85, 201 (2018).

${ }^{55}$ K. Kukli, M. Kemell, M. J. Heikkilä, H. Castán, S. Dueñas, K. Mizohata, M. Ritala, and M. Leskelä, Nanotechnology 31, 195713 (2020).

${ }^{56}$ S. Dueñas, H. Castán, H. García, Ó. G. Ossorio, L. A. Domínguez, and E. Miranda, IEEE Electron Devices Lett. 38, 1216 (2017). 